\title{
Chronic and Persistent Immune Thrombocytopenia: Guideline for Follow-up Care?
}

\author{
Prasad R. Koduri
}

Received: 9 June 2014/Accepted: 30 July 2014/Published online: 17 August 2014

(C) Indian Society of Haematology \& Transfusion Medicine 2014

Guidelines from several national societies $[1,2]$ and an international consensus statement [3] have addressed the management of immune thrombocytopenia (ITP) in great detail. The frequency of monitoring platelet counts in patients with chronic and persistent ITP however has not been addressed in existing guidelines and appears to depend on individual physician choice. Frequent platelet count determinations in these patients in absence of symptoms, or intercurrent febrile illness may lead to unnecessary anxiety for the patient and unneeded physician visits. This is particularly relevant for patients living in areas of the country with poor medical access. Until prospective studies establish recommendations in this regard, a consensus view could be developed by the Indian Society of Hematology and Blood Transfusion on the frequency and indications for routine platelet count monitoring in patients with chronic or persistent ITP.

\section{References}

1. Neunert C, Lim W, Crowther M, Cohen A, Solberg L Jr, Crowther MA, American society of hematology (2011) The American society of hematology 2011 evidence-based practice guideline for immune thrombocytopenia. Blood 117:4190-4207
2. The Indian Society of Hematology and Blood Transfusion (ISHBT) (2011) Consensus guidelines for immune thrombocytopenia. http://ishbt.org/wp-content/uploads/guide.pdf. version 1.0 Accessed Nov 2011

3. Provan D et al (2010) International consensus report on the investigation and management of primary immune thrombocytopenia. Blood 115:168-186
P. R. Koduri $(\bowtie)$

The Division of Hematology-Oncology, Mediciti Hospital, Secretariat Road, Hyderabad 500063, India

e-mail: prkoduri@yahoo.com 